\title{
A perda do protagonismo histórico do trabalho e as favelas
}

The loss of labor's historic leading role and slums

Luiz Antonio Machado da Silva [l]

\begin{abstract}
Resumo
Este texto apresenta um esquema do quadro de vida atual nas grandes cidades brasileiras, tendo como foco, de início, o mundo do trabalho e, em seguida, o lugar das periferias, mais particularmente das favelas. 0 fio condutor da reflexão são as formas de regulação e controle constituídas pelas relações de coprodução entre os aparatos do Estado e a configuração da população e da ordem urbana. Trata-se de uma perspectiva, uma linha de reflexão, esquemática e básica (ou seja, mais estrutural do que conjuntural), que procura articular as grandes tendências de mudança que caracterizam o momento presente.
\end{abstract}

Palavras-chave: tendências de transformação; regulação social; controle social.

\begin{abstract}
This text presents a scheme of the current life scenario in the large Brazilian cities, focusing first on the world of labor and then on the place of peripheries, particularly of slums. The reflection is driven by the forms of regulation and control constituted by co-production relations between the State's apparatuses and the configuration of population and urban order. It is a perspective, a line of reflection, that is schematic and basic (that is, structural rather than conjunctural) and attempts to articulate the great trends of change that characterize the current moment.
\end{abstract}

Keywords: transformation trends; social regulation; social control. 


\section{Introdução}

Decidi usar esta oportunidade para apresentar um esquema do quadro de vida atual nas grandes cidades brasileiras, tendo como foco, de início, o mundo do trabalho e em seguida o lugar das periferias, mais particularmente das favelas. Neste momento, minha intenção não é oferecer ao leitor um produto acabado, até porque, considerando o espaço de um artigo, esta seria uma tarefa impossível. Quero apenas oferecer uma perspectiva, uma linha de reflexão, esquemática e básica (ou seja, mais estrutural do que conjuntural), que procura articular uma série de tendências - nenhuma das quais, isoladamente, é desconhecida - que possam vir a ser, no longo prazo, preenchidas com os detalhes sócio-históricos pertinentes e, assim, sustentada empiricamente. Serei, portanto, minimalista, com a finalidade de destacar os aspectos mais básicos do argumento geral - 0 que implica eliminar referências bibliográficas, citações, etc.

0 fio condutor da reflexão que apresento adiante são as formas de regulação e controle $\mathrm{e}^{1}$ constituídas pelas relações de coprodução entre os aparatos do Estado e a configuração da população e da ordem urbana partindo, em particular, da questão secular dos processos de segregação social. Em consequência do caráter esquemático deste artigo, trabalho com um "antes" e um "agora", e evito associar o "agora" ao sentimento muito generalizado (e mais do que razoável) de que o mundo está em crise, uma vez que o considero inespecífico e, dessa maneira, sociologicamente intratável. Como conceito, uma crise abstrata e geral não tem sentido: "crise", em termos concretos e sociologicamente manipuláveis, demanda inúmeros atributos e qualificações específicas que não aceitam abstrações. Esse comentário é tanto mais verdadeiro quando a ideia de revolução parece estar consensualmente sepultada ou, pelo menos, se for aceita a hipótese que adoto neste texto, de intensa fragmentação do conflito inerente às relações sociais. (A revolta de 2013 pode ser considerada um bom exemplo da crítica social na atualidade, com as ruas sendo tomadas por uma "multidão separada" não apenas por demandas muito específicas, mas, principalmente, por demandas claramente contraditórias).

Para fechar esta pequena introdução, antecipo que trabalharei com três níveis de generalidade:

a) o perfil sociocultural e econômico das maiores cidades brasileiras derivado das grandes transformações econômicas mundiais das últimas décadas. É fato que o impacto das mudanças na economia mundial é refratado pelas condições nacionais, regionais e locais que 0 neologismo "glocal" procura expressar. Porém, como o peso dos processos mundiais é muito forte, não trato desta questão. Reconheço que ela é uma simplificação problemática.

b) a natureza da polícia e do policiamento, enquanto principal mediação institucional entre a esfera macro e o controle imediato das rotinas cotidianas. A relevância da polícia como a mediação principal, com a atividade policial de certa maneira substituindo a esfera política e, com isso, configurando as periferias, é uma característica específica da atualidade. Também aqui há uma simplificação talvez exagerada, uma vez que existem inúmeras polícias com funções diferentes atuando nas grandes cidades brasileiras. Nesta reflexão, penso apenas 
no policiamento ostensivo e, portanto, privilegio a polícia militar.

c) o caso particular das favelas, que são tomadas como representando as periferias urbanas, tanto no esquema aqui apresentado quanto para o senso comum. Uso o termo periferia com um sentido mais social do que espacial, uma vez que também existem "periferias internas", como é o caso de muitas favelas.

\section{As grandes transformações econômicas e o perfil sociocultural das cidades brasileiras $^{2}$}

Os processos conjugados de globalização/financeirização, isto é, a hegemonia mundial do capital financeiro, somados à terciarização e à terceirização que acompanham a perda da relevância político-econômica da indústria, tem provocado importantes mudanças nas relações de trabalho. Há um intenso processo de precarização, além de um crescente aumento do desemprego, que também tem atingido setores das camadas médias que, no passado recente, estavam protegidos, e da deriva de grandes massas de trabalhadores e trabalhadoras que se tornaram irrelevantes como força de trabaIho para a acumulação. Todos esses sub-processos são bem conhecidos e dispensam maiores explicações. Quero apenas fazer um acréscimo aos discursos de crise. Em primeiro lugar, as questões ligadas à redução drástica da proteção do trabalho parecem tender a ser abafadas pelo entendimento muito generalizado de que os problemas econômicos derivam apenas de uma crise fiscal do Estado brasileiro (federal e estadual), o que tem aberto espaço para uma saraivada de propostas ultraliberais, muitas vezes efetivamente incorporadas, produzindo um círculo vicioso que enreda a economia em uma espiral de desinstitucionalização, ou informalização, das relações trabalhistas. Socialmente, as principais consequências são as seguintes:

- 0 intenso e generalizado processo de desinstitucionalização da economia tem como contrapartida o desenvolvimento de um hiper-individualismo. Dessa forma, os processos de subjetivação apoiam-se em referências cada vez mais reduzidas, com a família despontando como o principal vetor. Entretanto, deve ser acrescentado que não se trata exatamente da família como um valor moral transcendente, mas da "minha" família. Em suma, as referências simbólicas do processo de subjetivação são fortemente abaladas, com impacto crescente (e negativo) sobre os processos de integração social. (Retorno a esta consequência adiante.)

- Do ponto de vista político, praticamente desaparece a referência secular à noção de classe social, que por muito tempo esteve na base da formação das ações coletivas e, com isso, garantia uma certa convergência e polarização da luta social. Isso não elimina os protestos, movimentos e demais formas de crítica social capitaneadas pelos trabalhadores e trabalhadoras (quanto ao capital, ele apenas tentava assimilar a crítica ou fugir dela), nem tampouco desqualifica a noção de classe como conceito.

- Essa perda de enraizamento social da noção de classe como um valor moral compartilhado, mesmo sem eliminar a crítica social, tem como consequência, juntamente com a desinstitucionalização da economia, a progressiva fragmentação do processo de integração social. Essa tendência a uma integração 
fragmentada não liberta completamente o capital da obrigação de responder às críticas nem as enfraquece, mas garante a estabilidade geral do sistema e lhe confere o lugar de protagonista histórico das transformações sociais, lugar que até pouco tempo era ocupado pelo trabalho, mesmo como o ator subalterno do processo de acumulação que sempre foi. Em outras palavras, as críticas tornam-se reativas, e não mais propositivas.

- Paralelamente ao desenvolvimento do que chamei acima de hiper-individualismo, surge também uma profunda mudança na ética do trabalho. Cada vez menos é a atividade laboral em si que sustenta a moralidade coletiva dos trabalhadores e trabalhadoras, que vem sendo substituída pela capacidade de gerar rendimentos para a reprodução familiar, a chamada "ética do provedor". Essa restrição da moralidade deixa amplo espaço para a desconsideração dos meios de reprodução como fontes, eles também, de valor moral e, com isso, obriga o fortalecimento do controle repressivo no nível da vida cotidiana.

- Entretanto, se, em conjunto, os processos de fragmentação característicos da atualidade acima esboçados reforçam enormemente a hegemonia do capital financeiro e dão a impressão de "fim da história", há uma forte tendência subterrânea a contrarrestar esse "regime (socioeconômico e político) pós-salarial". Trata-se do desinteresse pela política de grande parte dos participantes do mundo popular. A crescente desconexão entre o Estado e uma parcela significativa da sociedade, que expressa a redução da esfera pública e tende a atribuir à polícia, por sua capacidade coatora, a garantia maior da reprodução da ordem social, demonstra a fragilidade disso que venho chamando de "integração fragmentada".

\section{A natureza da polícia e do policiamento}

Pelos comentários acima, fica claro o papel cada vez mais importante da polícia, que aos poucos vai substituindo a política para grandes contingentes à deriva, que perderam as condições de participar plena e regularmente da vida coletiva e que, através da atividade policial, ficam limitados às periferias. Entretanto, acho necessário acrescentar uma palavra a mais sobre a natureza dessa instituição, que aprofunda o problema da reprodução social na atualidade. Quero sugerir que a polícia, dentre todos os aparatos estatais, é o mais claramente pré-moderno, embora formalmente esteja organizada em termos modernos como os demais aparatos.

Militarizada ou não, a polícia pode ser, do ponto de vista formal, considerada uma burocracia estatal com a função principal de garantia, pelo uso da força moderada, da ordem pública - e, de fato, tem exercido essa atividade de contenção com um zelo que muitas vezes é exagerado. Mas é necessário considerar como a polícia organiza-se internamente ao efetivar sua função.

Uma burocracia moderna é aquela que expropria de seu corpo administrativo um tipo particular de conhecimento e produz uma série de protocolos que visam regular sua efetivação independentemente dos interesses particulares dos membros. Dada esta separação, espera-se que o burocrata desenvolva uma atividade 
impessoal: ele deve fazer o que esses protocolos determinam. No caso da polícia (pelo menos da brasileira), sua atuação não segue esse caminho. No desempenho da função repressora que lhe cabe, o conjunto dos policiais apropria-se da função de policiamento, e se organiza na forma de cliques que estão sempre em competição pelos melhores postos para a busca dos interesses particulares desses grupos de policiais. As determinações oficiais a respeito de sua atuação podem combinar-se ou não com os objetivos do grupo, mas esta é uma característica subsidiária da organização interna da polícia. Proponho que isto seja verdadeiro em especial para a polícia militar, que é encarregada da atividade coatora.

Não quero com esses comentários sugerir que os policiais têm liberdade absoluta para agir. Apesar de uma ampla autonomia, eles são limitados, de um lado, pelas hierarquias formais, muito embora essas barreiras nem sempre funcionem e possam ser atravessadas com a formação das cliques acima mencionadas, as quais em geral reúnem policiais com diferentes posições institucionais. De outro lado, há um limite simbólico, que é uma questão também crucial, porém menos rígida e difícil de determinar. Trata-se da relação entre o ethos corporativo da polícia e a cultura dominante. Esses dois conjuntos de valores e orientações das condutas interagem através da mídia e tendem para uma compatibilização, particularmente no plano dos costumes. Na verdade, é justamente esta homogeneização que fundamenta a ampla margem de liberdade da atuação policial, embora isto não impeça um certo desprezo pela corporação como um todo, devido à conhecidíssima truculência de suas práticas e à contaminação decorrente do contato reiterado com os estratos subalternos.

\section{As favelas como caso particular das preferias}

Quero terminar focalizando diretamente as favelas que, nos comentários da primeira seção, desaparecem, assimiladas ao termo "trabalho".

Durante bastante tempo, as favelas gozaram de presença cada vez maior no debate público, seguindo um processo de inserção na cidade que eu chamei de integração subordinada e acompanhando, à sua maneira, o protagonismo do trabalho. Entretanto, a partir de um certo momento difícil de precisar (talvez em torno dos anos 1990), esse movimento histórico se inverte, apesar da resistência das organizações faveladas que, inclusive, se complexificam e começam a criar um braço reflexivo, provável consequência da elevação geral do nível educacional, que já chega até mesmo à pós-graduação, embora ainda em raros casos. De qualquer maneira, é possível dizer que durante um período de mais de cem anos as favelas atravessaram grandes variações na conjuntura como uma força social atuante e politicamente significativa.

Independentemente do sucesso ou insucesso pontual dos favelados na luta contra as diferentes formas de desqualificação moral e social, as favelas sempre buscaram o reconhecimento como legítima parte das cidades onde existem. Conseguiram muitos avanços neste sentido, não obstante jamais tenham atingido plena cidadania urbana, o "direito à 
cidade". Na realidade, essa inserção ambígua e conflitiva na cidade parece ser a fonte mais básica dos processos de controle e segregação que sofrem.

Como quer que seja, olhando o conjunto dessa secular luta das favelas e seus moradores contra a segregação, cabe uma pergunta em três tempos:

- Considerando que é sabido que as formas de desqualificação moral da pobreza têm sido bastante variadas ao longo do tempo, porque é sempre nas favelas que os atributos negativos são colados?

- E se, como parece, esses atributos podem estar associados genericamente à desmoralização da pobreza, porque as favelas os concentram sempre, sabendo-se que os territórios da pobreza têm configuração bastante variada?

- E por que esses atributos, de maneira contra-intuitiva, substituem-se um aos outros ao longo do tempo, ao invés de se somarem, como seria de esperar, já que tanto a forma quanto o status jurídico das favelas continuam basicamente os mesmos?

Proponho que só haja uma resposta possível para essa capacidade das favelas de concentração variável de atributos negativos. Trata-se da visibilidade espacial das favelas, ${ }^{3}$ derivada da clara inferioridade de seus padrões construtivos, muito mais nítida do que outros territórios da pobreza que também se constituem como "periferias internas" (casas de cômodos, por exemplo), somada à sua longa atuação política, que reforça a percepção visual. Na realidade, têm havido movimentos reivindicativos nas demais áreas segregadas, em alguns casos bastante intensos, mas parece que a sustentação no tempo de coletividades politicamente atuantes é mais difícil nesses casos. Em suma, a visibilidade espacial das favelas, de que os demais territórios da pobreza não gozam, presta-se para conferir-Ihes o lugar de um tropo, uma metáfora, para as questões que articulam os aspectos espaciais e morais do conflito em torno da integração urbana a cada momento.

Esta é uma das razões pelas quais os órgãos responsáveis pela definiç̧ão e contagem das favelas nunca lograram uma definição consistente e aceita sem reserva. Por tratar-se de uma metáfora em um conflito cujo conteúdo tem sido bastante variável, não é possível uma abordagem direta, sem mediação simbólica, dessa região moral que não admite reificação.

\section{Um comentário final sobre as favelas}

Para terminar, quero retornar a um comentário anterior sobre o nível educacional dos moradores de favela, que parece revestir-se de grande importância.

Até por volta de uma década atrás, 0 movimento dos favelados permaneceu pouco reflexivo. Suas lideranças sempre foram muito ciosas de sua autonomia política e organizacional, porém, contraditoriamente, apenas adaptavam o discurso e as práticas das esquerdas partidariamente organizadas. Em palavras mais duras, a insistente defesa da autonomia pelas lideranças faveladas acabava não sendo mais do que aparência, pelo menos como tendência geral.

No entanto, parece que esse quadro está mudando, e mesmo mudando aceleradamente. Há um fenômeno relativamente recente e tão 
intenso que já tem sido bastante comentado. No bojo da elevação generalizada do nível educacional, cada vez mais há moradores com nível universitário, embora seja ainda uma pequena minoria. (Esse é um aspecto que parece ter relação direta com o debate sobre ações afirmativas.)

Provavelmente esse fenômeno esteja na base do aparecimento e multiplicação de um braço reflexivo nas organizações de militância política das favelas. Se a prevalência (e urgência) da prática e a rígida defesa da autonomia implicavam muita desconfiança e rejeição às universidades, ONGs e partidos, atualmente tem havido muita "parceria" com essas organizações, sempre sob a coordenação dos próprios favelados. Mesmo as tradicionais associações de moradores que, incidentalmente, perderam muito de sua antiga representatividade devido aos conflitos e, em menor escala, à cooptação pelas facções ligadas ao varejo de drogas ilícitas, têm se aproximado de pessoas e grupos de corte mais reflexivo. Também tem crescido rapidamente grupos voltados para a recuperação da história e da memória das lutas travadas pelas diferentes localidades. Além dessas novidades na orientação da prática política, tem havido a formação de diversificados grupos ligados ao que poderia ser chamado de autovalorização cultural, os quais proliferam em todas as periferias, não apenas nas favelas.

Em suma, as periferias parecem atravessar uma dupla tendência de mudança nas suas modalidades de atuação. Seus coletivos demonstram maior grau de autoconfiança, 0 que lhes permite interagir com grupos não favelados sem medo de perder a identidade, ao mesmo tempo que empreendem um movimento de "culturalização" das práticas coletivas. Essa transformação ocorre em um contexto altamente desfavorável. Creio que resta saber - que eu saiba, não há pesquisas sistemáticas a respeito dessas tendências - se essa mudança antecipa um avanço das práticas coletivas das favelas e demais periferias ou, inversamente, um abrandamento da atividade crítica desses segmentos.

\section{[I] https://orcid.org/0000-0001-8197-1316}

Universidade do Estado do Rio de Janeiro, Instituto de Estudos Sociais. Rio de Janeiro, RJ/Brasil. machadodasilvaluizantonio@gmail.com 


\section{Notas}

(1) Esses termos, no presente trabalho, não são sinônimos: enquanto regulação indica regras com procedimentos negociados, controle indica regras unilateralmente definidas. Esses dois aspectos sempre aparecem em conjunto, de modo que o uso de cada um desses dois termos indica tão somente a prevalência de um ou de outro. Quero também mencionar que todas as instituições, estatais ou não, são atoras nesse duplo processo de produção da ordem social. Nesse terreno, todas as diferenciações são meramente analíticas e se baseiam na prevalência de um ou de outro aspecto. Obviamente, a polícia (ver as referências adiante) destaca-se na administração do controle.

(2) Esta sessão baseou-se, entre vários outros trabalhos, principalmente nos seguintes textos: Perruso e Araújo, (2015); Postone (2014); Rancière (1998); Wood (1995).

(3) Há bastante favelização nas "periferias externas", porém o contraste dos padrões construtivos, e mesmo do status jurídico, é menor e dificultam sua percepção.

\section{Referências}

PERRUSO, M. A. e ARAÚJO, M. da S. (orgs.). (2015). Ciência e política-memórias de intelectuais. Rio de Janeiro, Mauad/Faperj.

POSTONE, M. (2014). Tempo, trabalho e dominação social. São Paulo, Boitempo.

RANCIÈRE, J. (2012) [1998]. Aux bords du politique. Paris, FolioEssais.

WOD, E. M. (2003 [1995]. Democracia contra capitalismo. São Paulo, Boitempo.

Texto recebido em 14/dez/2018

Texto aprovado em 10/jan/2019 